\title{
Pengaruh Pembayaran Non Tunai Terhadap Jumlah Uang yang Diminta Masyarakat
}

${ }^{1}$ Ayu Nursari, Fakultas Ekonomi dan Bisnis (FEB) Universitas Lampung (Unila), Indonesia

2 I Wayan Suparta, Fakultas Ekonomi dan Bisnis (FEB) Universitas Lampung (Unila), Indonesia

${ }^{3}$ Yoke Moelgini, Fakultas Ekonomi dan Bisnis (FEB) Universitas Lampung (Unila), Indonesia

\section{Informasi Naskah}

Submitted: 19 Agustus 2019

Revision: 20 Oktober 2019

Accepted: 5 September 2019

\section{Kata Kunci:}

Kartu Debet/ATM, Kartu Kredit, E-money, Kliring, RTGS, PDB, M1

\begin{abstract}
Technological developments have touched aspects of life, including the economic sector of the banking sector. Along with advances in financial technology, commercial transactions continue to experience changes in the pattern and payment system (payment), which influences facilitate the reach of the public with bank financial products. Currently, the role of cash payments has begun to be shifted to technology advances. The purpose of this study was to determine the effect of noncash fees (Debit / ATM Cards, Credit Cards, E-Money, Clearing, RTGS) on the economy and demand for cash in Indonesian society. This study uses Bank Indonesia (BI) and the Central Statistics Agency (BPS). The research data used is quarterly time data with 2013 sample time: 1 to 2018: 4. The data analysis technique used is the Error Correction Model (ECM) and Trend Analysis. The study results show that non-cash payments (Debit / ATM Cards, Credit Cards, E-Money, Clearing, RTGS) have a positive effect on the economy and demand for cash in Indonesian society.
\end{abstract}

\begin{abstract}
Abstrak
Perkembangan teknologi telah menyentuh aspek kehidupan termasuk sektor ekonomi perbankan.Seiring dengan kemajuan teknologi finansial, transaksi ekonomi terus mengalami perubahan pada pola dan sistem pembayaran (payment) yang pengaruhnya mempermudah jangkauan masyarakat dengan produk keuangan bank.Saat ini peranan pembayaran uang tunai mulai tergeser dengan adanya kemajuan teknologi. Tujuan penelitian ini adalah untuk mengetahui pengaruh pembayaran non tunai (Kartu Debit/ATM, Kartu Kredit, E Money, Kliring, RTGS) terhadap perekonomian dan permintaan uang tunai di masyarakat Indonesia. Penelitian ini menggunakandata yang bersumber dari Bank Indonesia (BI) dan Badan Pusat Statistik (BPS).Data penelitianyang digunakan adalah data time seriestriwulan dengan sampel waktu 2013 : 1 sampai dengan 2018 : 4.Teknik analisis data yang digunakan adalah Eror Correction Model (ECM) dan Analisis Trend.Hasil penelitian menunjukkan bahwapembayaran non tunai (Kartu Debit/ATM, Kartu Kredit, E Money, Kliring, RTGS) berpengaruh positif terhadap perekonomian dan permintaan uang tunai di masyarakat Indonesia.
\end{abstract}




\section{PENDAHULUAN}

Seiring dengan kemajuan teknologi finansial, transaksi ekonomi terus mengalami perubahan pada pola dan sistem pembayaran (payment) yang pengaruhnyamempermudah jangkauan masyarakat dengan produk keuangan bank dan lembaga keuangan non bank. Saat ini peranan pembayaran uang tunai mulai tergeser dengan adanya kemajuan teknologi. Kondisi demikian juga telah mendorong berkembangnya alat pembayaran dari cash based menjadi non cash based. Perkembangan teknologi telah menyentuh aspek kehidupan termasuk sektor ekonomi. Bentuk inovasi pelayanan bank berupa pelayanan electronic transaction (e banking) melalui sistem pembayaran non tunai dengan menggunakan kartu (Kartu debet/ATM, kartu kredit) dan uang elektronik (e money) serta transaksi Kliring dan RTGS.

Berdasarkan kajian yang dilakukan oleh Costa dan Grauwe (2001), penggunaan alat pembayaran non tunai secara luas memiliki implikasi pada berkurangnya pemintaan uang terhadap uang yang diterbitkan Bank Sentral, base money yang pada gilirannya dapat mempengaruhi pelaksanaan tugas Bank Sentral dalam melaksanakan kebijakan moneter. Hal yang sama juga dikemukakan oleh Freidman (1999), perkembangan teknologi informasi akan memberikan implikasi terhadap berkurangnya peran base money dalam transaksi pembayaran.

Gambar 1.

\section{Perkembangan Peredaran Uang}

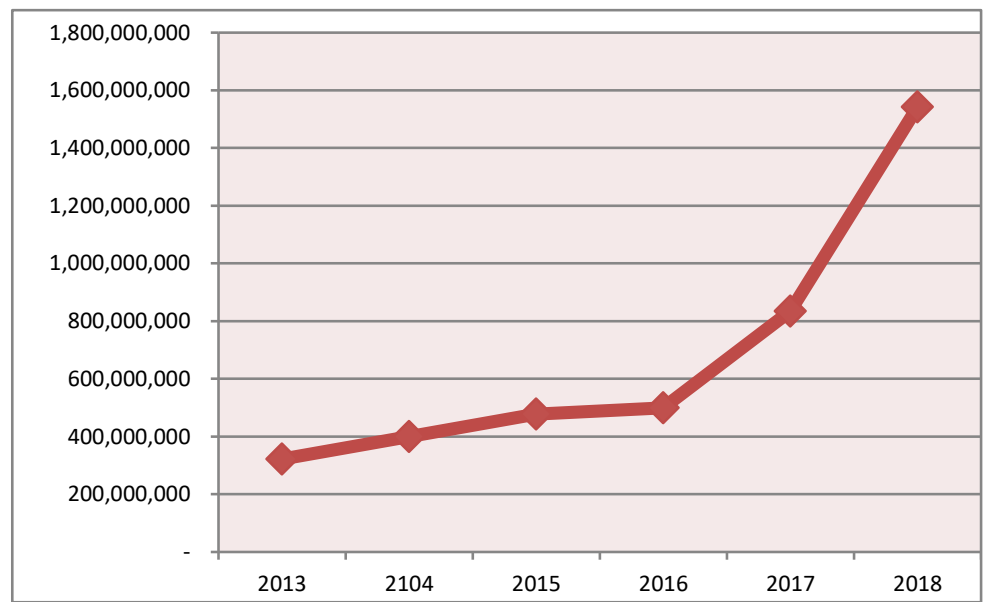

Sumber: Bank Indonesia, data diolah (2019)

Sebagaimana terlihat dalam Gambar 1, jumlah uang beredar dalam arti sempit (M1) mengalami peningkatan dari waktu ke waktu selama periode tersebut.Kehadiran alat pembayaran non tunai bagi perekonomian memberikan manfaat peningkatan efisiensi dan produk-tifitas keuangan yang mendorong aktifitas sektor rill pada gilirannya dapat mendorong pertumbuhan ekonomi dan meningkatkan kese-jahteraan masyarakat (Pramono et al, 2006). Di Indonesia pengguna e money tumbuh secara signifikan yang tercermin dari data volume dan nominal transaksi pada tahun 2017 yang diterbitkan Bank Indonesia. Nominal transaksi uang elektronik mencapai Rp. 10,42 triliun. Kemunculan e-money ditengah masyarakat bertujuan untuk mengurangi tingkat pertumbuhan penggunaan uang tunai.

Kehadiran alat pembayaran non tunai berbentuk kartu berpotensi untuk mendorong kenaikan tingkat konsumsi. Kenaikan konsumsi akhirnya akan mempengaruhi peningkatan pendapatan nasional dan dapat mendorong meningkatnya permintaan uang (money demand). Dari sisi produsen peningkatan konsumsi berpotensi mendorong aktifitas usaha dan ekspansi. Dari sisi pemerintah penggalakan penggunaan pembayaran non tunai dalam jangka panjang dapat menghemat biaya cetak uang.

Peningkatan pembayaran non tunai akan mempengaruhi permintaan uang dan keseimbangan di pasar uang, serta output dan harga, yang tentunya mempunyai implikasi terhadap pengendalian moneter. Perubahan tingkat suku bunga, output dan harga tersebut tentunya akan di respon oleh Bank Indonesia dalam bentuk pengendalian moneternya.

Berdasarkan uraian latar belakang diatas dan fenomena di Indonesia maka penulis 
tertarik untuk melakukan penelitian dengan judul:"Pengaruh Pembayaran Non Tunai Terhadap Jumlah Uang Yang Diminta Masyarakat (M1) Dan Perekonomian".

Sistem pembayaran adalah suatu sistem yang mencakup pengaturan, kontrak/perjanjian, fasilitas operasional, dan mekanisme teknis yang digunakan untuk penyampaian, pengesahan dan penerimaan instruksi pembayaran, serta pemenuhan kewajiban pembayaran melalui pertukaran "nilai" antarperorangan, bank, dan lembaga lainnya baik domestik maupun antarnegara (Subari \& Ascarya 2003). Dalam prakteknya, transaksi pembayaran dilakukan dengan instrumen tunai dan nontunai. Sistem pembayaran merupakan bagian yang tidak terpisahkan dari sistem keuangan dan perbankan suatu negara.

Pembayaran non tunai adalah pembayaran yang dilakukan tanpa menggunakan uang tunai yang beredar melainkan menggunakan cek atau bilyet giro (BG) dan berupa sistem pembayaran elektronik berbasis kartu yang dapat mengganti peranan uang kartal.Pembayaran non tunai dalam penggunaannya melibatkan jasa perbankan. Perbankan selaku badan usaha penghimpun dana masyarakat selayaknya memberikan pelayanan lalu lintas pembayaran yang dapat membanatu dalam pemenuhan kebutuhan ekonomi nasabah.

Electronic payment system merupakan penerapan teknologi pada sistem pembayaran agar aktifitas perbankan lebih cepat, tepat, akurat yang akhirnya akan meningkatkan produktifitas perbankan. Sistem pembayaran ini pun berkembang menjadi electronic payment system, dimana sistem pembayaran elektronik ini memanfaatkan teknologi dalam bertransaksi, misalnya kartu debit dan kartu kredit.(Warjiyo, Perry.2006).

Teori permintaan uang Keynes mendasarkan pada adanya dua motif memegang uang kas, yakni motif transaksi dan spekulasi. Motif transaksi tergantung dari pendapatan. Sedangkan, motif spekulasi tergantung dari tingkat bunga. Perkembangan selanjutnya dari teori Keynes ini didasarkan atas dua pembagian tersebut, yang masing-masing dilakukan oleh William J. Baumol dan James Tobin.Pengaruh peningkatan pembayaran non-tunai tersebut terhadap permintaan uang kartal, M1, dan M2 juga dapat terjadi pada putaran berikutnya. Seiring dengan peningkatan GDP akibat peningkatan pembayaran non-tunai tersebut (diperkirakan), akan terdapat peningkatan permintaan uang kartal, M1, dan M2. Di sisi lain pembayaran non-tunai diperkirakan juga turut meningkat. Peningkatan GDP, uang kartal, M1, dan M2 tersebut tentunya perlu lag beberapa periode.

Dalam perekonomian tertutup, Keynes membagi permintaan agregat menjadi dua sektor yaitu sektor pengeluaran rumah tangga (C) dan pengeluaran swasta berupa Investasi (I).Sedangkan pada tiga sektor, ditambah dengan pengeluaran pemerintah (G). Untuk perekonomian terbuka, Keynes memasukan unsur factor luar negeri yaitu berupa sektor dan impor yang sering disebut ekspor netto $(X-M)$

\section{METODOLOGI PENELITIAN}

Bagian ini berisi desain atau desain penelitian yang dilakukan. Pada bagian ini, setidaknya berisi jenis penelitian, subjek / objek penelitian, teknik / instrumen pengumpulan data, dan analisis data. Jika skrip membutuhkan tabel atau gambar, gunakan contoh ini:

\section{Jenis dan Sumber Data}

Penelitian ini merupakan penelitian kuantitatif yang menekankan pada pengujian teori melalui pengukuran variable penelitian secara statistik untuk mengetahui pengaruh variable bebas Pembayaran Non Tunai (Kartu debet/ATM, kartu kredit, e money, kliring dan RTGS) terhadap variabel terikat (permintaan uang masyarakat (M1) dan perekonomian Indonesia). Pada penelitianini,data bersumber dari Bank Indonesia (BI) dan Badan Pusat Statistik (BPS). Data penelitianyang digunakan adalah data time seriestriwulan dengan sampel waktu $2013: 1$ sampai dengan $2018: 4$

\section{Metode Analisis Data}

Analisis yang digunakan dalam penelitian ini adalah Analisis Eror Correction Model (ECM) digunakan untuk mengidentifikasi pengaruh variabel pembayaran non tunai yaitu kartu 
debet/ATM,kartu kredit, e money, Kliring, dan RTGS terhadap perekonomian Indonesia dan permintaan uang (M1). Metode Eror Correction Model (ECM) dalam penelitian ini adalah :

$$
\begin{array}{ll}
\mathrm{PDB}_{\mathrm{t}} & =\beta_{0}+\beta_{1} N T K D_{t}+\beta_{2} N T K K_{t}+\beta_{3} N T E M_{t}+\beta_{4} N T K L_{t}+\beta_{5} N T G S t+\beta_{6} E C T_{6} \\
\mathrm{M}_{\mathrm{t}} & =\alpha_{0}+\alpha_{1} N T K D_{t}+\alpha_{2} N T K K_{t}+\alpha_{3} N T E M_{t}+\alpha_{4} N T K L_{t}+\alpha_{5} N T G S t+\alpha_{6} E C T_{6}
\end{array}
$$

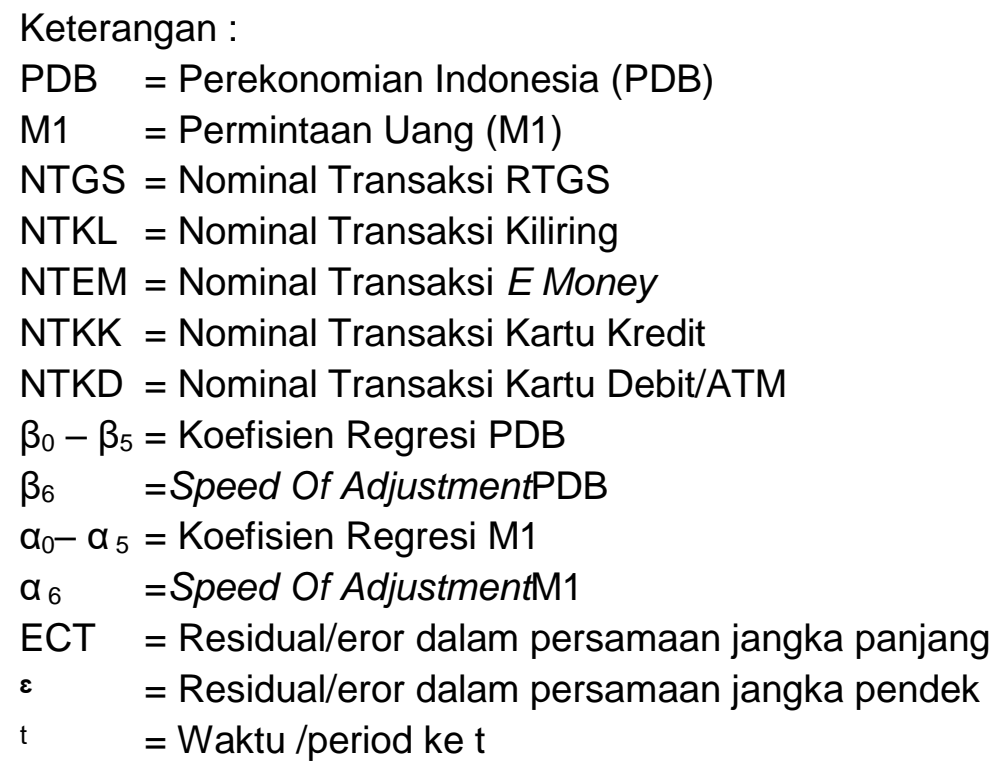

Dalam penelitian ini juga digunakanmetode Trend Kuadrat Terkecil (Least SquareMethod) untuk mengidentifikasi efek dari perubahan waktu terhadap jumlah uang yang beredar di masyarakat. Rumus perhitungannya:

$$
\begin{array}{ll}
Y & =a+b X \\
b & ={ }^{n} \sum X Y-\sum X Y \\
{ }^{n} \sum X Y^{2} & -\left(\sum X Y\right) \\
a & =\frac{\sum Y}{n}-\frac{b \sum X}{n}
\end{array}
$$

Keterangan:

$\mathrm{Y}=$ adalah nilai dari ramalan dengan trend.

$\mathrm{a} \quad=$ nilai tetap (konstanta) atau nilai $\mathrm{Y}$ pada $\mathrm{X}$ sama dengan nol.

$\mathrm{b} \quad=$ kemiringan (slope) atau perubahan nilai $\mathrm{Y}$ dari waktu ke waktu

$\mathrm{X} \quad=$ Periode waktu ke waktu

\section{HASIL DAN PEMBAHASAN}

\section{Uji Stasionaritas}

Pada penelitian ini, langkah pertama yang dilakukan adalah melihat kestasionaritasan data yang digunakan dengan melakukan uji stasionaritas.

Berdasarkanhasil uji stasionaritas data, terdapat tiga variabel tidak stasioner di tingkat level, kemudian dilakukan uji stasioneritas pada tingkat first difference yang diperoleh hasil satu variabel tidak stasioner. Maka dilakukan uji stasionaritas pada tingkat second difference dan diperoleh hasil yang bahwa semua varabel stasioner dengan nilai probabilitas lebih kecil dari $0.05(5 \%)$. 
Tabel 1.

Hasil Uji Root PDB

\begin{tabular}{|c|c|c|c|c|c|c|}
\hline \multirow[t]{2}{*}{ Variabel } & \multicolumn{2}{|c|}{ Level } & \multicolumn{2}{|c|}{ First Difference } & \multicolumn{2}{|c|}{$\begin{array}{l}\text { Second } \\
\text { Difference }\end{array}$} \\
\hline & ADF & Prob. & ADF & Prob. & ADF & Prob. \\
\hline NTKD & 0,05 & 0.7483 & 0,05 & 0.0000 & 0,05 & 0.0000 \\
\hline NTKK & 0,05 & 0.4685 & 0,05 & 0.6037 & 0,05 & 0.0000 \\
\hline NTEM & 0,05 & 0.9999 & 0,05 & 0.0046 & 0,05 & 0.0000 \\
\hline NTKL & 0,05 & 0.0302 & 0,05 & 0.0000 & 0,05 & 0.0002 \\
\hline NTGS & 0,05 & 0.0198 & 0,05 & 0.0001 & 0,05 & 0.0013 \\
\hline PDB & 0,05 & 0.9882 & 0,05 & 0.0000 & 0,05 & 0.0000 \\
\hline
\end{tabular}

Sumber: Hasil Estimasi Menggunakan Eviews 8

Tabel 2.

Hasil Uji Root M1

\begin{tabular}{lllll}
\hline Variabel & \multicolumn{2}{c}{ Level } & & \multicolumn{2}{c}{ First Difference } \\
\cline { 2 - 5 } & ADF & Prob. & ADF & Prob. \\
\hline NTKD & 0,05 & 0.7000 & 0,05 & 0.0000 \\
NTKK & 0,05 & 0.4304 & 0,05 & 0.0000 \\
NTEM & 0,05 & 1.0000 & 0,05 & 0.0086 \\
NTKL & 0,05 & 0.0356 & 0,05 & 0.0000 \\
NTGS & 0,05 & 0.0046 & 0,05 & 0.0000 \\
M1 & 0,05 & 0.8366 & 0,05 & 0.0000 \\
\hline
\end{tabular}

Sumber: Hasil Estimasi Menggunakan Eviews 8

Berdasarkan hasil uji stasionaritas data, terdapat tiga variabel tidak stasioner di tingkat level, kemudian dilakukan uji stasionaritas pada tingkat first difference diperoleh hasil yang bahwa semua varabel stasioner dengan nilai probabilitas lebih kecil dari 0.05 (5\%).

Secara ekonomi, variabel terkointegrasi merupakan kondisi terkait hubungan jangka panjang antara variabel variabel tersebut dapat untuk mengevaluasi ketidakseimbangan jangka pendek.

Dalam persamaan jangka pendek hasil nilai $R^{2}$ sebesar 0,509646, yang artinya variabel nominal transaksi kartu debet/ATM, nominal transaksi kartu Kartu Kredit, nominal transaksi $E$ Money, nominal transaksi kliring dan nominal transaksi RTGS dan eror correction term (ECT) dalam persamaan jangka pendek secara bersama sama mempengaruhi variabel pendapatan domestik bruto (PDB) dalam perekonomian Indonesia sebesar 50,96\%, sementara sisanya sebesar $49.04 \%$ dipengaruhi faktor lain yang tidak dijelaskan dalam persamaan regresi.

Hasil penelitian menunjukkan bahwa variabel pembayaran non tunai sejalan dengan harapan jangka panjang dan jangka pendek. Nilai Nominal transaksi kartu debet/ATM, Nilai Nominal transaksi kartu Kartu Kredit, Nilai Nominal transaksi E Money, dan Nilai Nominal transaksi RTGS, bertanda Positif sedangkan Nilai Nominal transaksi kliring bertanda Negatif. Hal ini dapat disimpulkan bahwa semakin besar penggunaan pembayaran non tunai akan meningkatkan perekonomian Indonesia. Koefisien adjustment pada persamaan bernilai positif, yang artinya penyesuaian variabel nominal transaksi kartu debet/ATM, kartu nominal transaksi kartu kredit, nominal transaksi e-money, nilai dan nominal transaksi RTGS terhadap perekonomian Indonesia jangka pendek dan jangka panjang cukup tinggi. Kilring merupakan salah satu variabel yang belum mampu mewakili pergerakan pembayaran non tunai. 
Tabel 3.

Hasil Eror Correction Model (ECM)

\begin{tabular}{ccccc}
\hline \multicolumn{5}{c}{ Dependent Variabel: Perekonomian (PDB) } \\
$\begin{array}{c}\text { Independen } \\
\text { Variabel }\end{array}$ & Coefficient & t-Statistik & Prob. & Keterangan \\
C & & & & \\
NTKD & 0.003477 & 1.535237 & 0.1443 & \\
NTKK & 0.112323 & 1.754112 & 0.0985 & Signifikan \\
NTEM & 0.051104 & 0.601031 & 0.5562 & Tidak Signifikan \\
NTKL & 0.001218 & 0.073809 & 0.9421 & Tidak Signifikan \\
NKGS & -0.055924 & -2.697391 & 0.0159 & Signifikan \\
ECT & 0.111091 & 2.405871 & 0.0286 & Signifikan \\
R-Square & & & 0.0005 & Signifikan \\
Adjusted R-Square & & & 0.643379 & \\
F-Statistic & & & 0.509646 & \\
Prob. (Statistik) & & & 4.810924 & \\
\hline
\end{tabular}

Sumber: Hasil Estimasi Menggunakan Eviews 8 (Lampiran)

Tabel 4.

Hasil Hasil Eror Correction Model (ECM)

\begin{tabular}{ccccc}
\hline \multicolumn{5}{c}{ Dependent Variabel: Permintaan Uang (M1) } \\
$\begin{array}{c}\text { Independen } \\
\text { Variabel }\end{array}$ & Coefficient & $\begin{array}{c}\mathbf{t}- \\
\text { Statistik }\end{array}$ & Prob. & Keterangan \\
C & 0.003854 & 0,946936 & 0.3578 & \\
NTKD & 0.206794 & 1.834690 & 0.0852 & Tidak Signifikan \\
NTKK & 0.205537 & 1.291808 & 0.2148 & Tidak Signifikan \\
NTEM & 0.019444 & 0.655642 & 0.5214 & Tidak Signifikan \\
NTKL & -0.033988 & - & 0.3787 & Tidak Signifikan \\
& & 0.905303 & & \\
NKGS & 0.222682 & 2.672081 & 0.0167 & Signifikan \\
ECT & & & 0.0080 & Signifikan \\
R-Square & & & 0.616750 & \\
Adjusted R-Square & & & 0.473031 & \\
F-Statistic & & & 4.291362 & \\
Prob. (Statistik) & & & 0.009135 & \\
\hline
\end{tabular}

Sumber: Hasil Estimasi Menggunakan Eviews 8 (Lampiran)

Berdasarkan Tabel 4, diketahui nilai koefisien Eror Corecction Term (ECT) pada hasil estimasi persamaan jangka panjang signifikan dengan tingkat probabilitas sebesar $0,0080 \leq 0,05$ yang menunjukkan bahwa Eror Correction Model (ECM) yang digunakan valid, sedangkan nilai keseimbangannya menunjukkan 0,616750 yang dinyatakan bahwa proses penyesuaian terhadap kesimbangan permintaan uang di masyarakat Indonesia periode 2013-2018 dipengaruhi.

Dalam persamaan jangka pendek hasil nilai $R^{2}$ sebesar 0,473031 , artinya variabel nominal transaksi kartu debet/ATM, nominal transaksi kartu Kartu Kredit, nominal transaksi $E$ Money, nominal transaksi kliring dan nominal transaksi RTGS dan eror correction term (ECT) dalam persamaan jangka pendek secara bersama sama mempengaruhi variabel permintaan uang $47,30 \%$, sementara sisanya sebesar $52.7 \%$ dipengaruhi faktor lain yang tidak dijelaskan dalam persamaan regresi.

\section{Uji Asumsi Klasik}

1. Uji Multikolineritas

Pengujian Multikolineritas dilakukan dengan mengunakan uji VIF (Variance Inflation Factors) dengan melihat besaran hasil dari nilai VIF.

Berdasarkan Tabel 5.variabel bebas dikatakan saling berhubungan erat dengan variabel bebas lainnya jika nilai VIF lebih kecil dari 10. Pada penelitian ini dalam persamaan jangka pendek tidak terjadi masalah multikolineritas, namun dalam persamaan jangka panjang pada variabel kartu debet/ATM dan kartu kredit dengan nilai VIF lebih besar dari 10 yaitu variabel Kartu 
Debit dan Kartu Kredit. Permasalahan multikolineritas dapat diatasi dengan membiarkan data yang ada pada variabel dengan mempertimbangkan agar tidak merusak asumsi regresi (widarjono, 2005)

2. Uji Heterokedasitas

Pada penelitian ini digunakan uji metode Glejser, yang kemudian disajikan dalam hasil estimasi dari uji heterokedasitas, sebagai berikut:

Tabel 5.

Uji Multikolineritas

\begin{tabular}{llll}
\hline \multicolumn{2}{c}{ Persamaan Jangka Pendek } & \multicolumn{2}{c}{ Persamaan Jangka Panjang } \\
\hline \multicolumn{1}{c}{ Variabel } & Nilai VIF & \multicolumn{1}{c}{ Variabel } & Nilai VIF \\
\hline Kartu Debet/ATM & 1.183363 & Karu Debet/ATM & 12.27909 \\
Kartu Kredit & 1.358855 & Kartu Kredit & 14.57506 \\
E-Money & 1.099565 & LogE-Money & 4.905669 \\
Kliring & 1.309281 & Kliring & 2.315129 \\
RTGS & 1.320855 & RTGS & 3.625529 \\
\hline
\end{tabular}

Sumber: Hasil Estimasi Menggunakan Eviews 8

Tabel 6.

Uji Heterokedasitas

\begin{tabular}{lclc}
\hline \multicolumn{2}{c}{ Persamaan Jangka Pendek } & \multicolumn{1}{c}{ Persamaan Jangka Panjang } \\
\hline F-Statistic & 0.690942 & F-Statistic & 2.648682 \\
Obs*R-sqared & 4.733030 & Obs*R-sqared & 10.17296 \\
Scaled Explained SS & 3.672655 & Scaled Explained SS & 9.663590 \\
Prob F(5,66) & 0.6603 & Prob F(5,66) & 0.0579 \\
Prob. Chi-Square(5) & 0.5785 & Prob. Chi-Square(5) & 0.0705 \\
Prob. Chi-Square(5) & 0.7209 & Prob. Chi-Square(5) & 0.0853 \\
\hline
\end{tabular}

Sumber: Hasil Estimasi Menggunakan Eviews 8 (Lampiran)

Tabel 7.

Hasil UjiAutokorelasi

\begin{tabular}{lclc}
\hline \multicolumn{2}{c}{ Bruesche-Godfrey Serial Correlation LM Test } \\
\hline \multicolumn{2}{c}{ Persamaan Jangka Pendek } & \multicolumn{2}{c}{ Persamaan Jangka Panjang } \\
\hline F-Statistic & 1.392266 & F-Statistic & 0.838901 \\
Obs*R-Squared & 3.815670 & Obs*R-Squared & 2.277842 \\
Prob. (2,16) & 0,2809 & Prob. (2,16) & 0.4053 \\
Prob. Chi-Square(2) & 0,1484 & Prob. Chi-Square(2.) & 0.3202 \\
\hline
\end{tabular}

Sumber: Hasil Estimasi Menggunakan Eviews 8 (Lampiran)

Tabel 6. menunjukan tingkat nilai chi-square dari Obs* $R$-Squared pada persamaan jangka pendek sebesar 4.733030 atau $\geq 5 \%$. Sedangkan tingkat nilai chi-square dari Obs ${ }^{\star} R$-Squared pada persamaan jangka panjang sebesar 10.17296 atau $\geq 5 \%$, maka pada kedua persamaan tersebut tidak terdapat heterokedasitas.

3. Uji Autokorelasi

Pada penelitian ini pengujian dilakukan dengan menggunakan Bruesche-Godfrey Serial Correlation LM Test, Pengujian yang digunakan adalah Bruesche Godfrey serial corelation LM (Lagrange Multiplier) Test yang disajikan dalam Table 15 Diketahui nilai Prob. Cji Squared pada persamaan jangka pendek sebesar $0,1484 \geq 5 \%$ yang disim-pulkan tidak ada indikasi adanya autokorelasi. Persamaan jangka panjang nilai Prob. Cji Squared sebesar 0,3202 $\geq 5 \%$, yang artinya tidak ada indikasi adanya autokorelasi.

4. Uji Normalitas

Dalam penelitian ini metode yang digunakan untuk menguji nomarmalitas data adalah metode Jargue Beta Test (J.B.Test),

Hasil dari penelitian ini didapatkan nilai JB sebesar $0,517470 \geq 5 \%$, sehingga data residual dalam persamaan jangka pendek yang dihasilkan terdistribusi normal. Kemudian nilai JB sebesar 2,691465 atau $\geq 5 \%$ sehingga data residual dalam persamaan jangka panjang yang dihasilkan terdistribusi normal. 


\section{Analisis Trend}

Pada Gambar 3 baik sistem nominal transaksi Kartu Debit/ATM maupun nilai transaksi kartu kredit menunjukkan trend kenaikan selama periode pengamatan. Hal ini disebabkan semakin luasnya cakupan wilayah pelaksanaan dan penyempurnaan kartu debit/ATM dan kartu kredit, pembaharuan fitur fitur transaksi, efisiensi dalam bertransaksi, kemudahan dalam akses semua kebutuhan masyarakat yang semakin meningkatkan minat masyarakat untuk mengunakan jasa pembayaran tersebut.

Dibandingkan dengan instrumen non tunai lainnya penggunaan e-money masih belum signifikan meskipun pada dasarnya e-money memiliki potensi yang cukup besar. Dalam gambar dibawah ini ditunjukkan perkembangan transaksi menggunakane-money. Tahun 2017 mulai naik transaksi E money dengan inovasi teknologi seperti NFC, RFID,QR Code dll.

Mempercepat proses transaksi, menawarkan biaya lebih murah dan memberikan layanan yang lebih aman.

Selama periode pengamatan Gambar 4.nilai kliring dan RTGS menunjukkan trend yang tidak stabil. Penggunaan Cek dan BG terus menurun sementara penggunaan kartu cenderung meningkat. Transaksi kliring dan RTGS bisa menggunakan Cek/Bilyet Giro. Untuk kliring efektif dana adalah pukul 15.30 nasabah peserta kliring wajib mempunyai Giro dan menyiapkan sejumlah dana sesuai jumlah dana yang pada warkat Cek/Bilyet Giro, terdapat biaya bulanan serta biaya lainnya terkait hal tersebut. Rtgs transaksi di atas Rp. 100.000.000 sehingga tidak semua masyarakat menggunakan transaksi tersebut.Hal tersebut mempengaruhi pilihan masyarakat dalam bertransaksi

Perkembangan transaksi Non Tunai menunjukkan trend peningkatan dari waktu ke waktu selama periode penelitian. Peningkatan ini diprediksi akan terus meningkat sejalan dengan semakin beragamnya fasilitas dan fungsi yang di tawarkan oleh bank ataupun lembaga keuangan non bank yang berpengaruh dengan semakin meningkatnya produk domestik bruto (PDB) dalam perekonomian dan permintaan Uang.
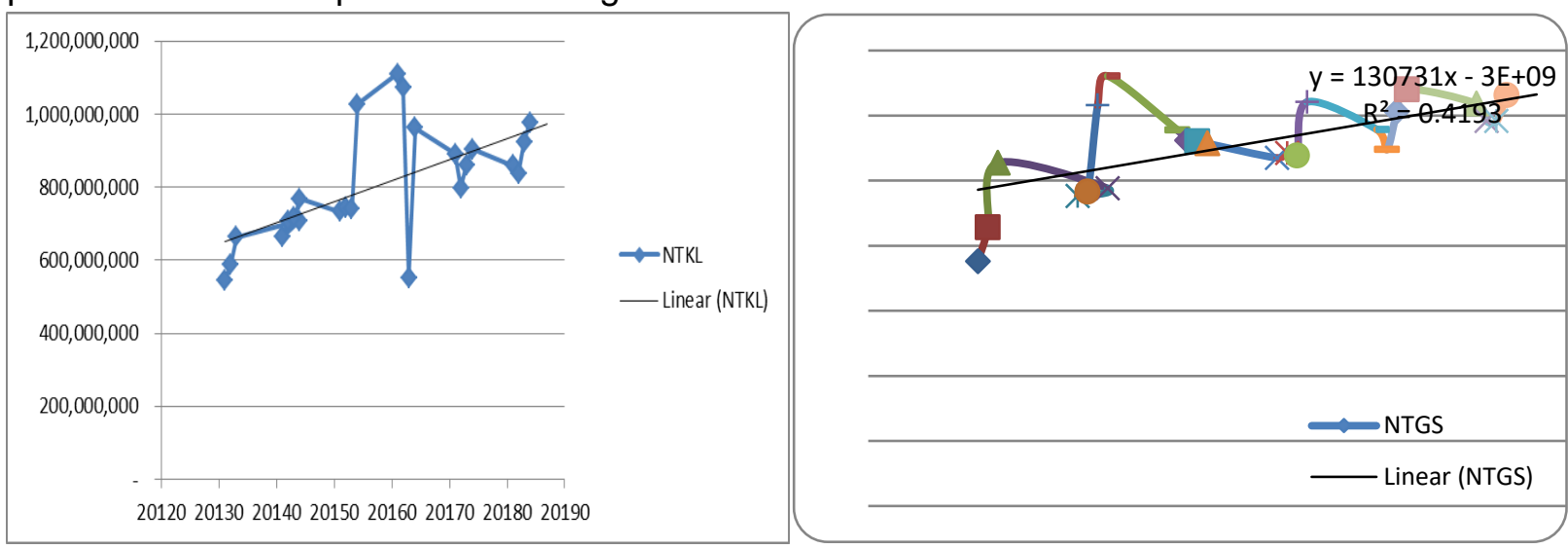

Sumber: Data Diolah (2019)

Gambar 5. Nominal Transaksi Kliring dan RTGS

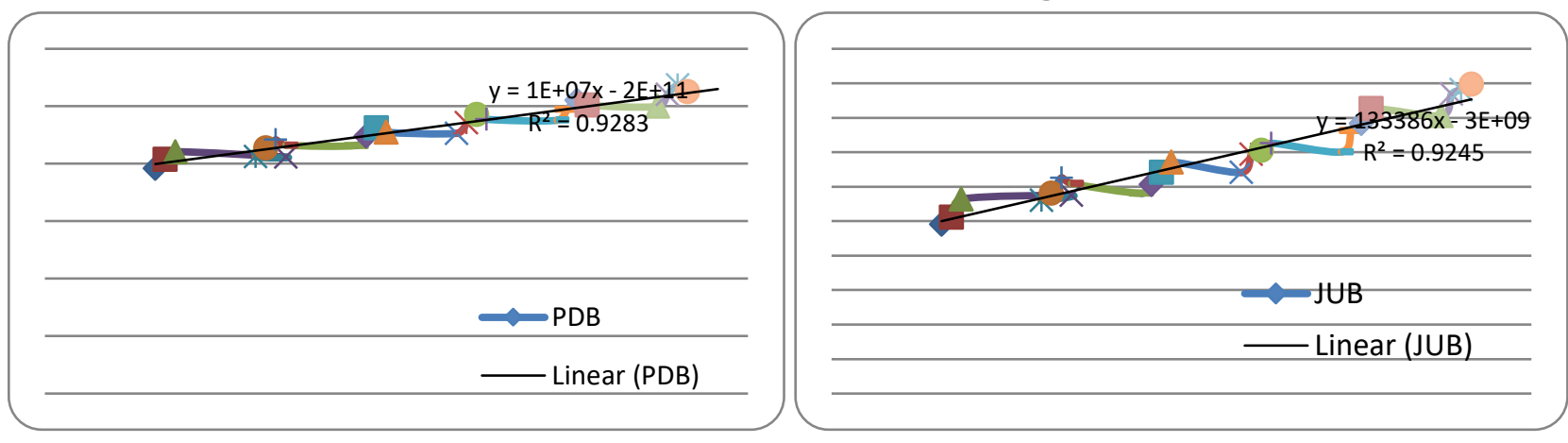

Sumber: Data Diolah (2019)

Gambar 6. Produk Domestik Bruto \& M1 
Pengaruh pembayaran non tunai (Kartu Debit/ATM, Kartu Kredit, E Money, Kliring, RTGS) terhadap perekonomian di Indonesia.

\section{Pengaruh Penggunaan Kartu Debit/Atm Terhadap Per-ekonomian Indonesia}

Pada periode penelitian bulan Januari 2013 sampai dengan Desember 2018 hasil perhitungan penelitian menunjukkan bahwa koefisien nominal transaksi kartu debit adalah sebesar 0.112323 yang artinya ketika nominal transaksi kartu debit mengalami peningkatan sebesar 1 trilyun produk domestik bruto (PDB) dalam perekonomian Indonesia akan mengalami peningkatan sebesar 0.112323 Milyar. Sesuai dengan penelitian Zandi et al (2016) meningkatnya penggunaan kartu debit dapat meningkatkan konsumsi dan PDB. Pengaruh tersebut disebabkan efek dari efisiensi yang ditimbulkan oleh pembayaran non tunai tersebut sehingga meningkatkan output dan pertumbuhan ekonomi (Syarifuddin et al, 2009). Selanjutnya hasil perhitungan penelitian jangka panjang menunjukkan bahwa koefisien nominal transaksi kartu debit/Atm adalah sebesar 0.2335895 yang artinya ketika nominal transaksi kartu debit/Atm mengalami peningkatan sebesar 1 trilyun maka produk domestik bruto (PDB) dalam perekonomian Indonesia akan mengalami peningkatan sebesar 0.2335895 Milyar. Hasil penelitian ini sejalan dengan penelitian dari hasan et al (2012) menyatakan bahwa beralih nya masyarakat menggunakan pembayaran non tunai dapat menstimulus pertumbuhan ekonomi.Oyewole et al (2012) bahwa transaksi menggunakan kartu debit/ATM memiliki hubungan positif terhadap pertumbuhan ekonomi.

\section{Pengaruh Penggunaan Kartu Kredit Terhadap Perekonomian Indonesia}

Berdasarkan hasil perhitungan penelitian jangka pendek menunjuk-kan bahwa koefisien nominal transaksi kartu debit adalah sebesar 0.163575 yang artinya ketika nominal transaksi kartu kredit mengalami peningkatan sebesar 1 Trilyun maka produk domestik bruto (PDB) dalam perekonomian Indonesia akan mengalami peningkatan sebesar 0.163575 Milyar. Sedangkan hasil perhitungan penelitian jangka panjang menunjukkan bahwa koefisien nominal transaksi kartu kredit adalah sebesar 0.163575 yang artinya ketika nominal transaksi kartu kredit mengalami peningkatan sebesar 1 Trilyun maka produk domestik bruto (PDB) dalam perekonomian Indonesia akan mengalami peningkatan sebesar 0.163575 Milyar.

Berdasarkan hasil estimasi penelitian diperoleh informasi dalam jangka pendek maupun jangka panjang variabel nominal transaksi kartu kredit memiliki koefisien positif dan tidak signifikan. Pengunaan kartu kredit hanya merupakan pola baru gaya hidup dan buka merupakan cara transaksi andalan masyarakat (Snellmanet al, 2009).

Dalam transaksi kartu kredit adanya tambahan bunga yang dibebankan oleh bank kepada pengunya, serta beberapa biaya lainnya untuk transaksi sehingga menjadi pilihan masyarakat untuk menggunakannya.

\section{Pengaruh Penggunaan E-Money Terhadap Perekonomian Indonesia}

Berdasarkan hasil perhitungan penelitian jangka pendek menunjukkan bahwa koefisien nominal transaksi e money adalah sebesar 0.001218 yang artinya ketika nominal transaksi e money mengalami peningkatan sebesar 1 Trilyun maka produk domestik bruto (PDB) dalam perekonomian Indonesia akan mengalami peningkatan sebesar 0.001218 Milyar. Sedangkan hasil perhitungan penelitian menunjukkan bahwa koefisien nominal transaksi e money adalah sebesar 0.028018 yang artinya ketika nominal transaksi e money mengalami peningkatan sebesar 1 Trilyun maka produk domestik bruto (PDB) dalam perekonomian Indonesia akan mengalami peningkatan sebesar 0.028018 Milyar.

Pembayaran elektronik yang paling jarang digunakan, dan baru diperkenalkan sebagai alat pertukaran atau pembayaran, tingkat literasi dan teknologi pembangunan di suatu Negara, antara lain menentukan efektivitas system pembayaran elektronik dan karenanya berhasil implementasi ekonomi tanpa uang tunai (Oginni, 2013). Mengacu pada pengalaman di beberapa Negara, E Money sebagai instrument pembayaran elektronik terbukti telah memberikan manfaat sebagai alternatif instrument pembayaran khususnya untuk pembayaran yang bersifat mikro dan ritel, hidayati (2006). 


\section{Pengaruh Penggunaan Kliring Terhadap Perekonomian Indonesia}

Berdasarkan hasil perhitungan penelitian jangka pendek menunjukkan bahwa koefisien nominal transaksi kartu debit adalah sebesar -0.055924 yang artinya ketika nominal transaksi kliring mengalami peningkatan sebesar 1 Trilyun maka produk domestik bruto (PDB) dalam perekonomian Indonesia akan mengalami penurunan sebesar 0,055925.

Selanjutnyan hasil perhitungan penelitian jangka panjang menunjukkan bahwa koefisien nominal transaksi kliring adalah sebesar 0.041867 yang artinya ketika nominal transaksi kliring mengalami peningkatan sebesar 1 Trilyun maka produk domestik bruto (PDB) dalam perekonomian Indonesia akan mengalami penurunan sebesar 0.041867 Milyar.Selanjutnya hasil estimasi penelitian diperoleh informasi dalam jangka pendek maupun jangka panjang variabel nominal transaksi kliring memiliki koefisien negatif dan signifikan pada jangka pendek dan koefisien negatif dan tidak signifikan pada jangka panjang. Hasil penelitian ini tidak sejalan dengan penelitian Pramono all (2006) menyatakan penggunaan pembayaran transaksi non tunai selain meningkatkan pendapatan masyarakat melalui penurunan biaya transaksi dan penghematan waktu juga meningkatkan pendapatan masyarakat melalui pendapatan bunga yang diperoleh dari dana kas yang seharusnya dibawa dalam setiap kali transaksi namun ditempatkan di bank dalam bentuk tabungan.

Penyelenggaraan Kliring juga tak luput dari kemungkinan risiko terjadinya gagal bayar. Dalan rangka mencegah terjadinya gagal bayar pada saat setelmen hasil kliring maka diwajibkan kepada setiap peserta untuk menyediakan sejumlah dana dengan jumlah tertentu setiap awal hari., dikarenakan transaksi non tunai tersebut menggunakan alat berupa cek/Bilyet Giro dan efektif dana kliring adalah pukul 15.30. Penggunaan kliring lebih kearah retail sehingga belum bisa merangkul semua kalangan masyarakat untuk menggunakan transaksi tersebut. Peserta kliring wajib mempunyai simpanan Giro di bank dan melakukan pengendapan atau menyimpan sejumlah dana di simpanan tersebut untuk kemudian dilakukan setelmen transaksi kliring.

\section{Pengaruh Penggunaan RTGS Terhadap Perekonomian Indonesia}

Berdasarkan hasil perhitungan penelitian jangka pendek menunjukkan bahwa koefisien nominal transaksi RTGS adalah sebesar 0.111090 yang artinya ketika nominal transaksi RTGS mengalami peningkatan sebesar 1 Trilyun maka produk domestik bruto (PDB) dalam perekonomian Indonesia akan mengalami peningkatan sebesar 0.111090 Milyar. Sedangkan hasil penelitian jangka panjang bulan Januari 2013 sampai dengan Desember 2018, Untuk nominal transaksi RTGS (NTGS) jangka panjang diperoleh nilai t-hitung sebesar -0.392002 dengan nilai probabilitas-t sebesar 0.6007 . Berdasarkan hasil penelitian diperoleh informasi dalam jangka pendek maupun jangka panjang variabel nominal transaksi RTGS memiliki koefisien positif dan signifikan pada jangka pendek dan koefisien positif dan tidak signifikan pada jangka panjang. Hal ini sesuai dengan penelitian yang dilakukan oleh Medyawati dan Hermana (2014) BI-RTGS mempengaruhi pertumbuhan ekonomi.

\section{Pengaruh pembayaran non tunai (Kartu Debit/ATM, Kartu Kredit, E Money, Kliring, RTGS) terhadap permintaan uang (M1) di masyarakat Indonesia. \\ Pengaruh Kartu Debit/ATM terhadap permintaan uang (M1) di masyarakat Indonesia.}

Berdasarkan hasil perhitungan penelitian jangka pendek menunjukkan bahwa koefisien nominal transaksi kartu debit adalah sebesar 0.206794 yang artinya ketika nominal transaksi kartu debit mengalami peningkatan sebesar 1 trilyun permintaan uang (M1) di masyarakat Indonesia akan mengalami kenaikan sebesar 0.112323 Milyar. Hal ini sejalan dengan penelitian Pramono et al 2006. Semakin besar penggunaan pembayaran non tunai akan menurunkan permintaan uang (M1).

Berdasarkan hasil perhitungan penelitian jangka panjang menunjukkan bahwa koefisien nominal transaksi kartu debit adalah sebesar 0.339913 yang artinya ketika nominal transaksi kartu debit mengalami peningkatan sebesar 1 trilyun permintaan uang (M1) di masyarakat Indonesia akan mengalami penurunan sebesar 0.339913 Milyar. Hal ini sesuai dengan penelitian yang dilakukan oleh Istanto S. Lasondy, \& Fauzie Syarief. 2014 bahwa Nilai Nominal Transaksi Kartu Debit/ATM berpengaruh positif terhadap M1 jangka panjang. 


\section{Pengaruh Kartu Kredit terhadap permintaan uang (M1) di masyarakat Indonesia.}

Berdasarkan hasil perhitungan penelitian menunjukkan bahwa koefisien nominal transaksi kartu kredit adalah sebesar 0.205537 yang artinya ketika nominal transaksi kartu kredit mengalami peningkatan sebesar 1 trilyun permintaan uang (M1) di masyarakat Indonesia akan mengalami kenaikan sebesar 0.205537 Milyar. Sedangkan hasil perhitungan penelitian jangka panjang menunjukkan bahwa koefisien nominal transaksi kartu debit adalah sebesar 0.113437 yang artinya ketika nominal transaksi kartu debit mengalami peningkatan sebesar 1 trilyun permintaan uang (M1) di masyarakat Indonesia akan mengalami kenaikan sebesar 0.113437 Milyar. Hal ini sejalan dengan penelitian Pramono et all 2006. Kartu kredit mempunyai arah negatif terhadap M1 karena dalam penggunaannya dapat menunjuk-kan kesadaran tingkat minat masyarakat akan kemudahan, keamanan dan keamanan sehingga melakukan subtitusi dalam melakukan pembayaran.

\section{Pengaruh E Money terhadappermintaan uang (M1) di masyarakat Indonesia.}

Berdasarkan hasil perhitungan penelitian menunjukkan bahwa koefisien nominal transaksi $E$ Money adalah sebesar 0.019444 yang artinya ketika nominal transaksi $E$ Money mengalami peningkatan sebesar 1 trilyun permintaan uang (M1) di masyarakat Indonesia akan mengalami penurunan sebesar 0.019444 Milyar. Sedangkan hasil perhitungan penelitian jangka panjang menunjukkan bahwa koefisien nominal transaksi $E$ Money adalah sebesar 0.081111 yang artinya ketika nominal transaksi $E$ Money mengalami peningkatan sebesar 1 trilyun permintaan uang (M1) di masyarakat Indonesia akan mengalami kenaikan sebesar 0.081111 Milyar. Hal ini sejalan dengan penelitian Sitorus 2006, dalam jangka panjang penggunaan transaksi $E$ Money berpengaruh positif terhadap transaksi tunai.

\section{Pengaruh Kliring terhadap permintaan uang (M1) di masyarakat Indonesia.}

Berdasarkan hasil perhitungan penelitian menunjukkan bahwa koefisien nominal transaksi Kliring adalah sebesar -0.033988 yang artinya ketika nominal transaksi Kliring mengalami peningkatan sebesar 1 trilyun permintaan uang (M1) di masyarakat Indonesia akan mengalami penurunan sebesar 0.033988 Milyar. Sealnjutnya hasil perhitungan penelitian jangka panjang menunjukkan bahwa koefisien nominal transaksi Kliring adalah sebesar 0.004218 yang artinya ketika nominal transaksi Kliring mengalami peningkatan sebesar 1 trilyun permintaan uang (M1) di masyarakat Indonesia akan mengalami peningkatan sebesar 0.004218 Milyar. Hal ini sejalan dengan Priyo (2012) menjelaskan bahwa pembayaran transaksi menggunakan Kliring tidak berpengaruh dalam jangka pendek dan jangka panjang tehadap perimintaan uang.

\section{Pengaruh RTGS terhadap permintaan uang (M1) di masyarakat Indonesia.}

Berdasarkan hasil perhitungan penelitian menunjukkan bahwa koefisien nominal transaksi RTGS adalah sebesar 0.222682 yang artinya ketika nominal transaksi RTGS (NTGS) mengalami peningkatan sebesar 1 trilyun permintaan uang (M1) di masyarakat Indonesia akan mengalami kenaikan sebesar 0.222682 Milyar. Selanjutnya hasil perhitungan penelitian jangka panjang menunjukkan bahwa koefisien nominal transaksi RTGS adalah sebesar 0.082835 yang artinya ketika nominal transaksi RTGS mengalami peningkatan sebesar 1 trilyun permintaan uang (M1) di masyarakat Indonesia akan mengalami kenaikan sebesar 0.082835Milyar.Penelitian Priscylia, 2014 perkembangan permintaan uang selalu meningkat fluktuasi dengan transaksi RTGS.

\section{Implikasi Pengaruh pembayaran non tunai (Kartu Debit/ATM, Kartu Kredit, E Money, Kliring dan RTGS ) terhadap permintaan uang (M1) di Masyarakat Indonesia.}

Dias (2009) menggambarkan efisiensi biaya transaksi dan menunggu dalam kurva biaya yang menggambarkan total biaya yang muncul dari aktivitas ekonomi yang dilakukan masyarakat yang diasumsikan terdiri dari biaya transaksi dan berjaga jaga dan biaya lainnya termasuk biaya menunggu, dengan mengasumsikan biaya transaksi sebagai biaya suatu biaya tetap, maka semakin lama interval atau durasi melakukan transaksi semakin tinggi biaya transaksi. Kehadiran alat pembayaran non tunai, seperti kartu Debit/Atm, Kartu Kredit, E Money, Kliring dan RTGS 
menurunkan opportunity cost untuk menyimpan uang di rumah dalam jumlah tertentu dan mengurangi waktu untuk menunggu melakukan transaksi yang terecrmin dari pergeseran kurva $\mathrm{C}_{\mathrm{t}}$ ke $\mathrm{C}_{\mathrm{t}}^{\prime}$ dan kurva $\mathrm{C}_{\mathrm{w}}$ ke $\mathrm{C}_{\mathrm{w}}$. Secara total, biaya transaksi akan turun dari $\mathrm{C}$ ke $\mathrm{C}^{\prime}$.

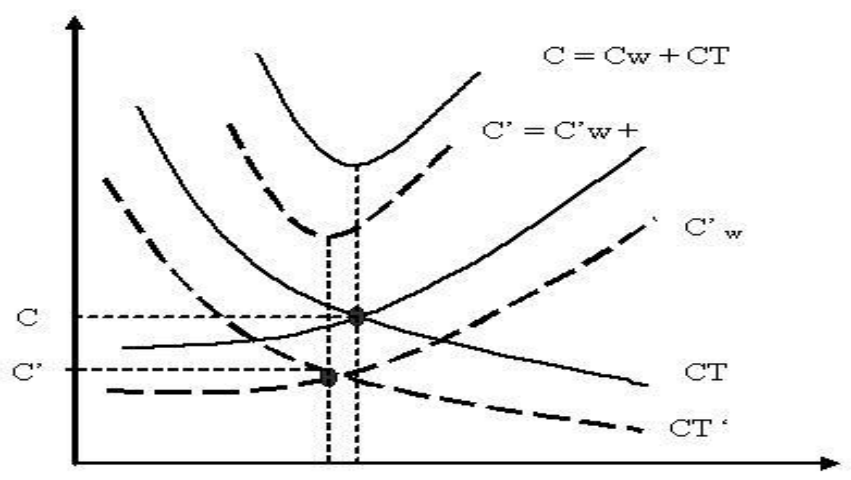

Interval (Durasi) Transaksi

Keterangan: $\quad C w=$ biaya menunggu

$C T=$ biaya transaksi

\section{Gambar 7. Kurva Biaya}

Sebagaimana di uraikan pada gambar 7.pembayaran non tunai akan menimbulkan efek subtitusi terhadap pembayaran tunai (maimun, 2016). Peningkatan penggunaan sistem pembayaran non tunai seperti Kartu debit/ATM, kartu Kredit, E Money, Kliring dan RTGS secara perlahan telah merubah pola hidup masyarkat dalam melakukan transaksi ekonomi.Peningkatan penggunaan system pembayaran non tunai secara perlahan telah merubah pola hidup masyarkat dalam melakukan transaksi ekonomi. Pembayaran non tunai menjadi pilihan masyarakat karena tidak perlu membawa uang tunai dalam jumlah besar, lebih aman dari pencurian, tidak ada uang palsu, bayar tagihan lebih mudah, lebih hemat, mempermudah belanja online, diterima diseluruh negara dan adanya dokumen pencatatan. Dengan adanya peningkatan pembayaran non tunai didukung oleh data bahwa penggunaan transaksi menggunakan APMK masih didominasi oleh penggunaan untuk tarik tunai dibandingkan dengan transaksi transfer ataupun belanja.

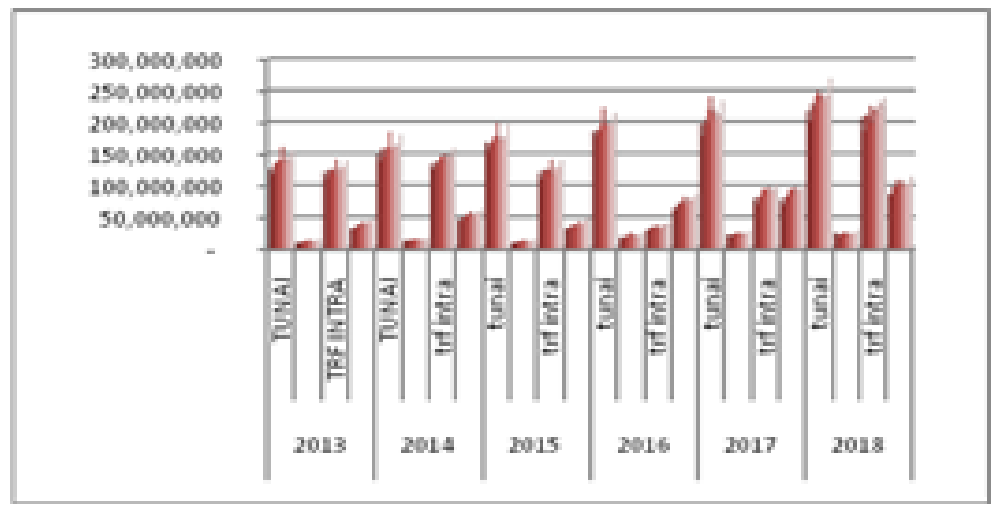

Sumber: Data diolah (2019)

\section{Gambar 8. Komposisi Jenis Transaksi APMK (Kartu Debit/ATM) periode 2013-2018}

\section{Implikasi Pengaruh pembayaran non tunai (Kartu Debit/ATM, Kartu Kredit, E Money, Kliring, RTGS) terhadap Perekonomian.}

Hasil penelitian meunjukan bahwa arah pembayaran non tunai telah sesuai denga teori ekonomi Keynesian. Apabila konsumsi masyarkat meningkat maka akan meningkatkan pendapat nasional bersama sama memberikan manfaat efisiensi dan peningkatan sector rill dalam mempengaruhi produk domestic bruto (PDB) dalam perekonomian Indonesia. Kemudahan dalam transaksi kegiatan ekonomi yang memiliki alat pembayaran non tunai dapat mendorong kenaikan 
konsumsi dari nasabah tersebut yang mendorong meningkatnya perekonomian. Pada Gambar

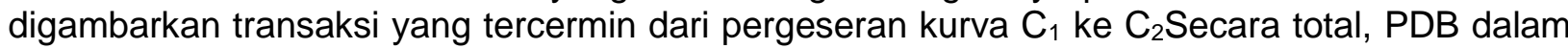
perekonomian akan naik dari $Y_{1}$ ke $Y_{2}$

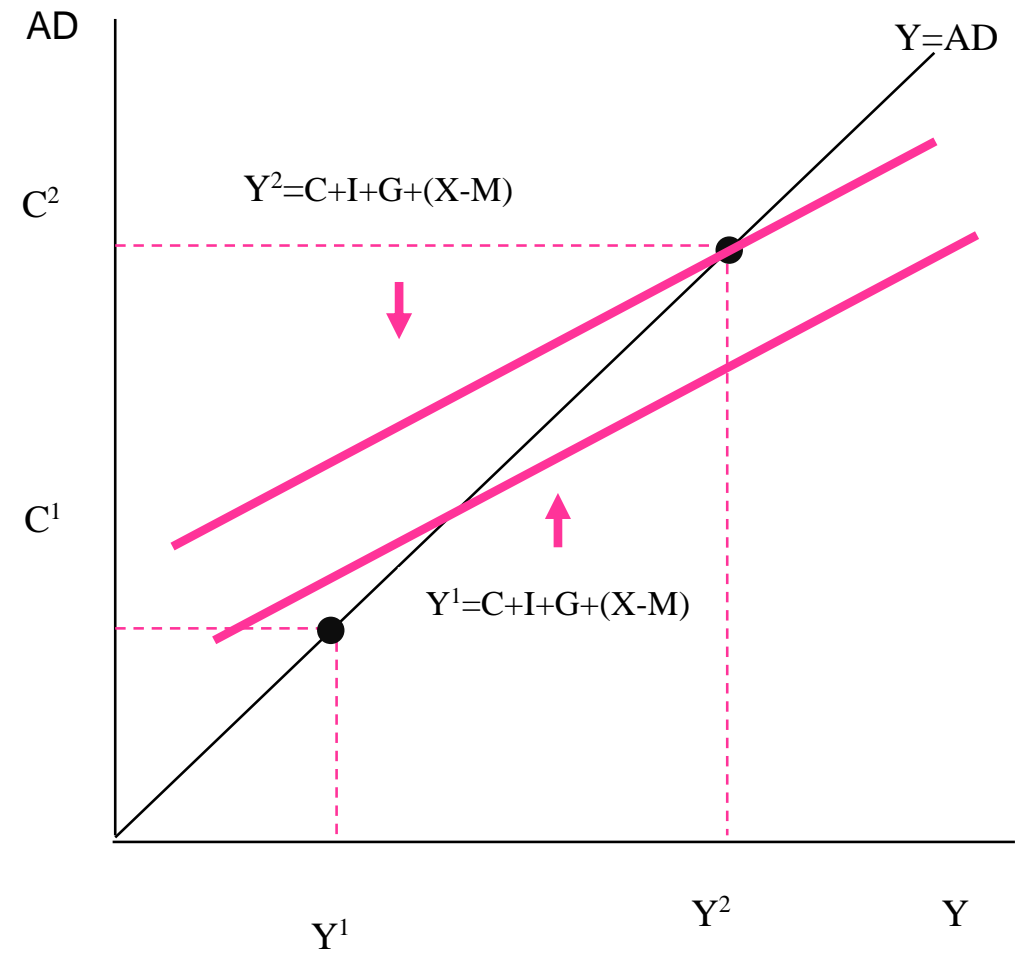

Gambar 9. Keynesian Crossing

\section{KESIMPULAN DAN SARAN}

\section{Kesimpulan}

Berdasarkan hasil pengolahan data dan pembahasan yang telah dilakukan, maka dapat disimpulkan sebagai berikut :

1. Pembayaran Non Tunai dalam jangka pendek nilai nominal transaksi Kartu Debit/ATM, nilai nominal transaksi kartu Kredit, nilai nominal transaksi E Money, nilainominal transaksi RTGS berpengaruh positif, secara bersama sama memberikan manfaat efisiensi dan peningkatan sector rill dalam mempengaruhi produk domestik bruto (PDB) dalam perekonomian Indonesia. Nilai nominal transaksi Kliring berpengaruh negatif belum mampu mempengaruhi produk domestik bruto (PDB) dalam perekonomian Indonesia.

2. Pembayaran Non Tunai dalam jangka panjang nilai nominal transaksi Kartu Debit/ATM, nilai nominal transaksi kartu Kredit, nilai nominal transaksi $E$ Money positif, secara bersama sama memberikan manfaat efisiensi dan peningkatan sector rill dalam mempengaruhi produk domestik bruto (PDB) dalam perekonomian Indonesia. Nilai nominal transaksi Kliring, dan nilai nominal transaksi RTGS berpengaruh negatif belum mampu mempengaruhi produk domestik bruto (PDB) dalam perekonomian Indonesia.

3. Pembayaran Non Tunai dalam jangka pendek nilai nominal transaksi Kartu Debit/ATM, nilai nominal transaksi kartu Kredit, nilai nominal transaksi E Money, nilainominal transaksi RTGS berpengaruh positif, secara bersama sama berpengaruh terhadap jumlah permintaan uang masyarakat (M1) Indonesia. Nilai nominal transaksi Kliring berpengaruh negatif terhadap permitaan uang (M1) masyarakat Indonesia..

4. Pembayaran Non Tunai dalam jangka panjang nilai nominal transaksi Kartu Debit/ATM, nilai nominal transaksi kartu Kredit, nilai nominal transaksi E Money, nilai nominal transaksi kliring dan nilainominal transaksi RTGS berpengaruh positif, secara bersama sama berpengaruh terhadap jumlah permintaan uang masyarakat (M1) Indonesia. 


\section{Saran}

1. Untuk Bank Indonesia agar kembali melakukan pemantauan dalam sistem pembayaran untuk keamanan transaksi non tunai,dan biaya transkasi yang diterapkan bank dan lembaga keuangan non bank agar semua lapisan masyarakat lebih tertarik menggunakan pembayaran non tunai. Perlu mengadakan sosialisasi secara menyelur terhadap masyarakat untuk menerapan less cash society.

2. Untuk perbankan dan lembaga keuangan bukan bank yang menerbitkan alat pembayran non tunai, agar lebih aktif melakukan sosialiasi terhadapa nasabah masing masing, baik mengenai fitur layanan, keamanan, biaya dll. Sehingga masyarakat akan mengetahi dengan jelas keuntungan yang didapatkan ketika menggunakan alat pembayaran non tunai.

3. Untuk Pemerintah Indonesia diharapkan penelitian ini dapat dijadikan acuan dalam meningkatkan teknologi (keamanan dan fitur) serta infrastruktur yang merata agar seua lapisan masyarakat dapat menggunakan transaksi non tunai.

4. Untuk peneliti selanjutnya disarankan untuk menambah tahun penelitian dan variabel variabel lain yang belum diteliti dalam penelitian ini. Melakukan perbandingan penelitian antara provinsi, kabupaten apakah dengan pembayaran non tunai mempengaruhi PDB dalam perekonomian di daerah masing masing.

\section{DAFTAR PUSTAKA}

Dias.Joilson. (2001). Digital Money: Review Of Literature and Simulation Of Welfare Improvement Of This Technological Advance. State University Maringa. Brazil.

Hasan, Iftekhar. Tania De Renzis \& Heiko Shmiedel. (2012). Retail Payments and Economic Growth. Bank Of Finlandia Research Discussion Papers 19.

Hidayati et al. (2006). Kajian Operasional E Money. Kajian Bank Indonesia.

Istanto S. Lasondy, \& Fauzie Syarief. (2014). Analisi Pengaruh Pembayaran Non Tunai Terhadap Jumalah Uang yang Beredar di Indonesia. Jurnal Ekonomi Keuangan. Vol. 2 No.

Oyewole, Oginni Simon, J. Abba, M \& Onuh M, E. (2013). Electronic Payment System and Economic Growth :Areview of Transition to Cashless Economy in Nigeria. International Journal Of Scientific Engineering and Technology, Vol. 2, ( No. 9).

Pramono, Bambang. Tri Yanuarti. Pipih D. Purusitawati \& Yesefin Tyas Emmy DK. (2006). Pengaruh Pembayaran Non Tunai Terhadap Perekonomian dan Pengendalian Moneter. Working Paper Bank Indonesia. No. 11.

Priscylia, Dona Anggia. (2014). Pengaruh Tingkat Bunga Srtifikat Bank Indonesia terhadap Permintaan Uang di Indonesia. Jurnal Ekonomi Pembangunan. Volume 12 no $2 \mathrm{Hal}$ 106-117.

Widarjono, Agus. (2005). Ekonometrika. Fakultas Ekonomi UII. Penerbit Ekonosia.

Zandi et al. (2016). The Impact of Electronic Payment on Economic Growth. Moody's Analytics. Canada. 